\title{
Remarkable Influence of Cobalt Catalysis on Epoxide Ring-Opening with Sulfoxonium Ylides
}

\author{
Megan L. Jamieson \\ Nicola Z. Brant \\ Margaret A. Brimble* \\ Daniel P. Furkert* \\ School of Chemical Sciences, The University of Auckland, \\ 23 Symonds St, Auckland 1010, New Zealand \\ d.furkert@auckland.ac.nz \\ Published as part of the Special Topic Cobalt in Organic Synthesis
}

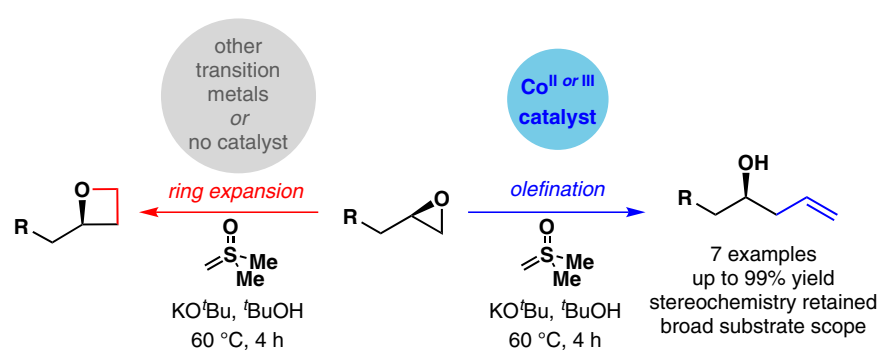

Received: 22.03.2017

Accepted after revision: 05.04.2017

Published online: 08.05 .2017

DOI: 10.1055/s-0036-1588814; Art ID: ss-2017-c0181-st

Abstract Cobalt demonstrates a remarkable ability to catalytically divert the course of epoxide to oxetane ring expansion via reaction with a sulfoxonium ylide. An expanded survey of transition-metal catalysts has confirmed that cobalt salts uniquely instead deliver homoallylic alcohol products from epoxides, with retention of the original epoxide stereochemistry. The reaction is an unusual example of cobalt-catalysed epoxide ring-opening by a carbon nucleophile. A tandem CoreyChaykovsky/epoxide olefination sequence giving homoallylic alcohols from aldehydes is further demonstrated along with preliminary mechanistic analysis. This communication summarises current understanding and ongoing studies into this intriguing new cobalt-mediated reactivity.

Key words cobalt catalysis, diverted reactivity, epoxide olefination, carbon-carbon bond formation, oxetane, Jacobsen HKR

Cobalt-based catalysts have been used to carry out a vast array of diverse carbon-carbon bond forming transformations, ${ }^{1}$ and have recently found successful application in the rapidly expanding field of selective $\mathrm{C}-\mathrm{H}$ activation. ${ }^{2}$ Currently, development of cobalt chemistry is encouraged by the availability, low toxicity, and chemical versatility of the metal, enabling discovery of novel and highly atomefficient processes. One particularly well studied example, the use of cobalt(salen) complexes for Jacobsen hydrolytic kinetic resolution (HKR) of epoxides has become a mature mainstay of asymmetric total synthesis due to its wide substrate scope, scalability, and reliability in enantioselective preparation of epoxides, ${ }^{3}$ including industrial applications. ${ }^{4}$ Recently, we reported that the known ring expansion of homochiral epoxide $\mathbf{1}$ using ylide 2 to give oxetane 3 , $^{5}$ was found to unexpectedly deliver homoallylic alcohol $\mathbf{4}$ as the sole product (Scheme 1). ${ }^{6}$ Careful investigation of the reagents eventually implicated traces of cobalt catalyst $\mathbf{5}$ (Figure 1 ) remaining from prior HKR of the epoxide as the caus- ative agent of this diverted reactivity. Rigorous removal of cobalt salts from 1 by Kugelrohr distillation restored the expected ring-expansion pathway to give oxetane 3. Control experiments also showed that re-submission of oxetane 3 to the reaction conditions gave no reaction, and therefore this compound was not an intermediate en route to 4. Our initial findings suggested that traces of other cobalt salts were similarly able to completely divert sulfoxonium ylide mediated ring expansion to homoallylic alcohols. In order to further confirm this finding, a wide range of transitionmetal catalysts have been screened for their influence on the reaction, under the optimised reaction conditions (Table 1). These data were observed to strongly corroborate the initial observation.

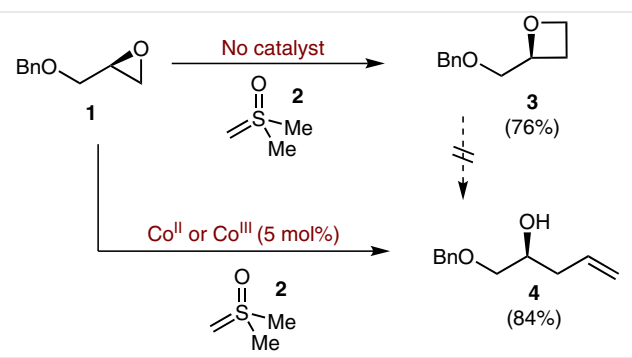

Scheme 1 Traces of cobalt salts divert the known ring expansion of epoxide 1 to oxetane 3 , instead delivering homoallylic alcohol 4. Reagents and conditions: trimethylsulfoxonium iodide (3 equiv), $t$-BuOK ( 3 equiv), $t$-BuOH, $60^{\circ} \mathrm{C}, 4 \mathrm{~h}$.

A number of catalysts that were examined either partially or completely suppressed the reaction of $\mathbf{1}$ to $\mathbf{3}$, returning unchanged starting material, epoxide $\mathbf{1}$ (Table 1 , entries 1-5). The majority of transition-metal-derived catalysts did not affect the normal course of the ring expansion reaction significantly, and complete conversion into oxetane 3 was observed (Table 1, entries 6-12). Remarkably, all 


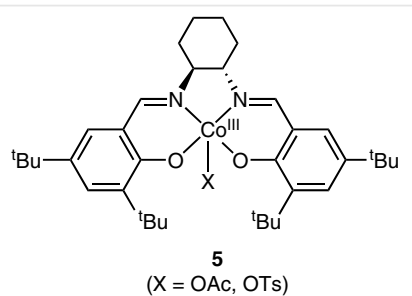

Figure 1 Jacobsen Co'l'(salen) hydrolytic kinetic resolution (HKR) catalyst

Table 1 Catalyst Influence on Epoxide Reactivity with Sulfoxonium Ylide $\mathbf{2}^{\mathrm{a}}$

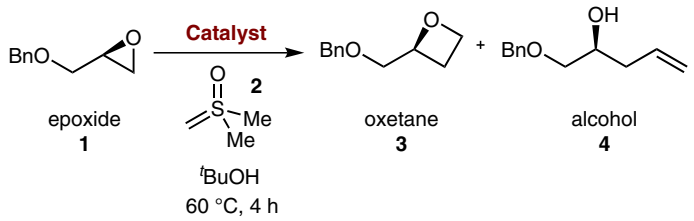

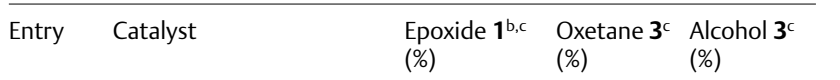

\begin{tabular}{|c|c|c|c|c|c|}
\hline 1 & & $\mathrm{BF}_{3} \cdot \mathrm{OEt}_{2}$ & 100 & & \\
\hline 2 & & $\left(\mathrm{PPh}_{3}\right)_{3} \mathrm{RhCl}$ & 100 & & \\
\hline 3 & & $\mathrm{Ni}(\mathrm{acac})_{2}$ & 100 & & \\
\hline 4 & & $\mathrm{ZnBr}_{2}$ & 80 & 20 & \\
\hline 5 & & $\mathrm{Ru}(\mathrm{acac})$ & 50 & 50 & \\
\hline 6 & & $\mathrm{FeCl}_{3}+$ bipy & & $98^{d}$ & \\
\hline 7 & & $\mathrm{Sc}(\mathrm{OTf})_{3}$ & & 100 & \\
\hline 8 & & $\mathrm{FeCl}_{3}$ & & 100 & \\
\hline 9 & & $\mathrm{CuCl}$ & & 100 & \\
\hline 10 & & $\mathrm{CuCl}_{2}$ & & 100 & \\
\hline 11 & & $\mathrm{PdCl}_{2}$ & & 100 & \\
\hline 12 & & $\mathrm{MnCl}_{2}$ & & 100 & \\
\hline 13 & & $\mathrm{CoCl}_{2} \cdot \mathrm{H}_{2} \mathrm{O}$ & & $47^{d}$ & $21^{d}$ \\
\hline 14 & \multirow{5}{*}{ 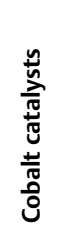 } & $\mathrm{CoCl}_{2}$ & & & 100 \\
\hline 15 & & $\mathrm{CoBr}_{2}$ & & & $72^{d}$ \\
\hline 16 & & $\mathrm{CoBr}_{2}+$ bipy & & & 100 \\
\hline 17 & & Co"(salen) & & & 100 \\
\hline 18 & & Co"'(salen)OAc 5 & & & $89^{d}$ \\
\hline
\end{tabular}

${ }^{a}$ Conditions: catalyst ( $\left.5 \mathrm{~mol} \%\right)$, trimethylsulfoxonium iodide (3 equiv), $t$-BuOK ( 3 equiv), $60^{\circ} \mathrm{C}, 4 \mathrm{~h}$.

b Unreacted starting material.

'Conversion estimated by ${ }^{1} \mathrm{H}$ NMR unless otherwise indicated.

${ }^{\mathrm{d}}$ Isolated yield.

cobalt salts investigated completely diverted the ring expansion to give homoallylic alcohol 4 (Table 1, entries 1318). The only exception was hydrated cobalt(II) chloride that partially promoted the diverted reaction (Table 1 , en- try 13), but the corresponding anhydrous salt gave full conversion to 4 . The presence of a ligand did not appear to affect the catalytic behaviour of the cobalt catalyst (Table 1 , entries 16-18). Both Jacobsen HKR cobalt(II) salen pre-catalyst and cobalt(III) salen $\mathbf{5}$ catalyst were effective.

The cobalt-catalysed epoxide olefination reaction proved to be broadly applicable among a range of substrates (Table 2) giving generally high yields of homoallylic products. Sterically demanding examples exhibited lower conversion rates, however (Table 2, entries 3-5). As might be expected, the original epoxide stereochemistry was retained in the products, confirmed by HPLC and Mosher ester analysis (Table 2, entries 1, 3, and 6). Given that the reaction conditions used in Table 2 are very similar to those of the Corey-Chaykovsky epoxidation of aldehydes, ${ }^{7}$ the potential of a tandem epoxidation-olefination sequence was also evaluated (Table 3). ${ }^{8}$ Overall, the transformation proved successful, giving clean conversion into homoallylic alcohols from both aliphatic and aryl aldehydes (Table 3, entries 1-4) and ketones (Table 3, entries 5 and 6) although a large excess of ylide and very long reaction times were found to be necessary to achieve this.

Table 2 Cobalt-Catalysed Epoxide Olefination (Selected Examples)a

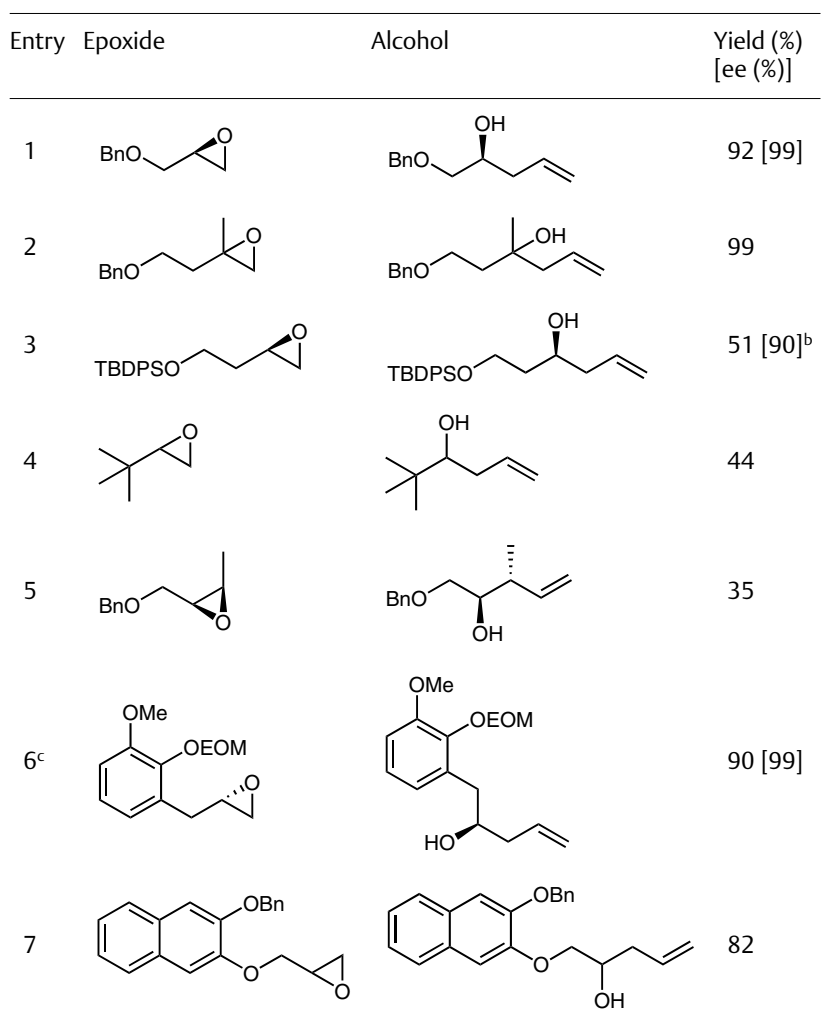

a Reaction conditions: Co"(salen) (5 mol\%), trimethylsulfoxonium iodide (3 equiv), $t$-BuOK ( 3 equiv), $t$ - $\mathrm{BuOH}, 60^{\circ} \mathrm{C}, 4 \mathrm{~h}$.

${ }^{\mathrm{b}}$ Epoxide starting material also $90 \%$ ee.

' $\mathrm{EOM}=$ ethoxymethyl. 
Table 3 Tandem Corey-Chaykovsky-Epoxide Olefination ${ }^{\mathrm{a}}$

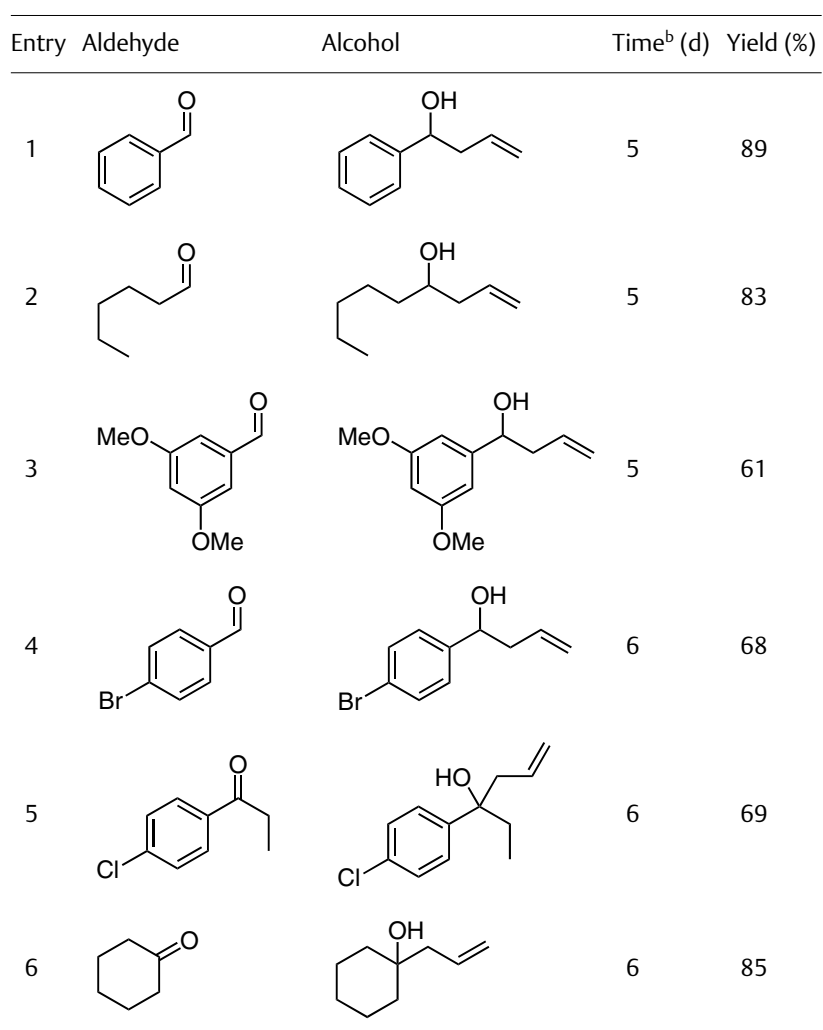

a Reaction conditions: Co"(salen) (10 mol\%), trimethylsulfoxonium iodide (10 equiv), $t$-BuOK (10 equiv), $t$-BuOH, $60^{\circ} \mathrm{C}$.

${ }^{b}$ Time to complete conversion by NMR.

Overall, the reaction mechanism likely follows the outline shown in Scheme 2. Initial ring-opening of epoxide $\mathbf{1}$ by sulfoxonium ylide 2 leads to intermediate betaine $\mathbf{6}$, that then cyclises to give ring-expanded oxetane $\mathbf{3}$, with the loss of dimethyl sulfoxide. In contrast, in the presence of cobalt salts, the reaction is diverted and $\mathbf{6}$ selectively undergoes a second addition of ylide $\mathbf{2}$, to afford homologated betaine $\mathbf{7}$ that in this case undergoes elimination to form homoallylic alcohol 4, similarly with the elimination of dimethyl sulfoxide. Interestingly, the seemingly plausible products of the converse processes, i.e. elimination from $\mathbf{6}$, or cyclisation from 7, have not been observed in these studies. In the tandem Corey-Chaykovsky/epoxide olefination sequence, the epoxide formation obviously requires an initial addition of ylide $\mathbf{2}$ to an aldehyde, although this extra step appears to significantly decrease the overall efficiency of the process.

The exact mechanistic details of the strong influence of cobalt salts on the reaction course remain unclear at present. Jacobsen cobalt(salen) HKR catalysts, including 5, have been demonstrated to accomplish asymmetric opening of meso epoxides and kinetic resolution of racemic terminal epoxides by the enantioselective addition of heteroatomic nucleophiles including azides ${ }^{9}$ and carboxylates. ${ }^{10} \mathrm{~A}$ num-

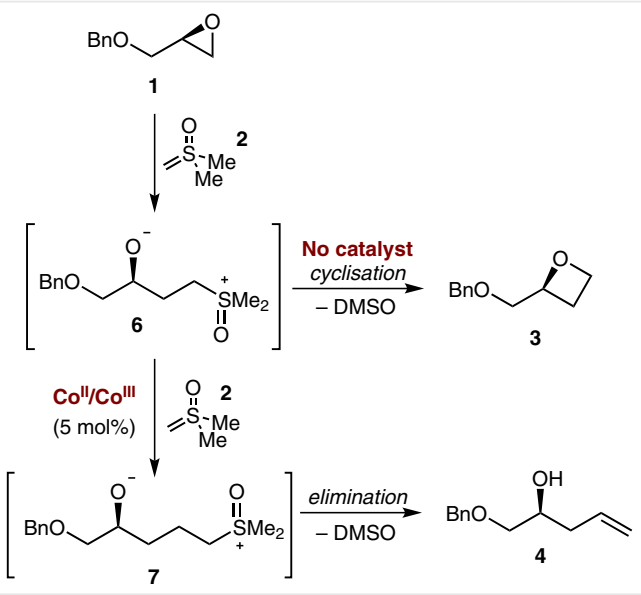

Scheme 2 Mechanistic overview of cobalt-catalysed epoxide olefination

ber of similar catalytic systems for closely related ringopening transformations of epoxides involving other heteroatomic nucleophiles have also been investigated. ${ }^{11}$ In contrast, the application of related systems involving cobalt and/or salen-based catalysts to carbon nucleophiles is largely restricted to carbonylative epoxide openings, although these reactions are highly useful and have been relatively well studied. ${ }^{12}$

In the context of these latter studies particularly, the successive addition of two equivalents of ylide $\mathbf{2}$ to epoxides under cobalt catalysis observed in this study is potentially significant, as both an important extension to known reactivity patterns and a mechanistic probe. In a series of reports detailing further improvements in catalytic systems for epoxide carbonylation, the Coates group propose a cooperative mechanism involving two metal centres. Coordination of the epoxide oxygen to a Lewis acid is suggested to promote epoxide opening by a low-valent cobalt species, followed by insertion of one of the carbonyl ligands into the Co bond (Scheme 3, A). ${ }^{13}$ Interestingly, this catalytic cycle bears strong resemblance to intermediates of the bimetallic catalytic cycle thoroughly elucidated for HKR catalyst $\mathbf{5}$ and derivatives by Blackmond and Jacobsen (Scheme 3, B). ${ }^{14}$ This latter work also identified the strong effect of the relative concentration of poorly Lewis acidic (salen) $\mathrm{Co}-\mathrm{OH}$ species on the efficiency of hydrolytic epoxide opening. It is plausible that a similar issue explains the observed partial ability of $\mathrm{CoCl}_{2} \cdot \mathrm{H}_{2} \mathrm{O}$ to divert the course of the epoxide ring expansion (Table 1 , entry 13 ). ${ }^{15}$

Sulfoxides are well-known ligands for transition metals and many metal-sulfoxide complexes are known. ${ }^{16}$ This might suggest that coordination of ylide 2 to cobalt could play a crucial role in delivering the nucleophile to an epoxide already activated by a second cobalt centre. ${ }^{17}$ 


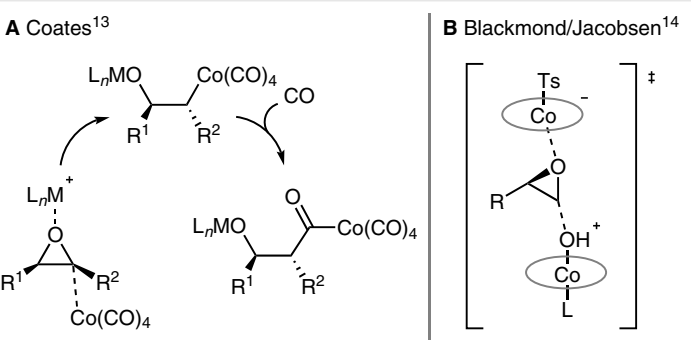

Scheme 3 Bimetallic cooperativity proposed in epoxide opening intermediates

Alternatively, sulfoxonium and sulfonium ylides form an emerging class of transition-metal-carbene precursors that behave as $\alpha$-diazocarbonyl equivalents in $\mathrm{C}=\mathrm{C}, \mathrm{C}-\mathrm{H}$, and $\mathrm{X}-$ $\mathrm{H}$ insertion reactions. ${ }^{18}$ This suggests the possibility that association of ylide $\mathbf{2}$ with the cobalt catalyst might lead to formation of an intermediate cobalt carbene species that could potentially undergo insertion into the epoxide substrate, following activation by a second cobalt centre. Related catalytic cycles involving dimethylsulfoxonium ylides have been proposed for gold- and iridium-based systems. ${ }^{19}$ Further, an unusually stable example of a high-valent carbene complex of the type that might be required for this mechanism was recently prepared and characterised by Xray crystallography. ${ }^{20}$ Notably in this report, attempts using the same methodology to form the corresponding iron complex were unsuccessful.

In conclusion, it has been demonstrated that cobalt salts catalytically divert the expected course of the reaction of epoxides with sulfoxonium ylides. Evaluation of other transition-metal catalysts has to date shown that only cobaltbased catalysts possess this activity, which provides synthetically useful access to enantiopure homoallylic alcohols. The reaction is an unusual example of cobalt(salen)catalysed epoxide ring-opening by a carbon nucleophile. Continuing efforts are underway to elucidate the mechanistic aspects and further implications of these findings including kinetic studies, identification of reaction intermediates and extended reaction scope.

All reactions were performed under an atmosphere of $\mathrm{O}_{2}$-free $\mathrm{N}_{2}$ using standard anhydrous techniques. Reagents were used as received unless otherwise noted. $t$-BuOH was distilled from $\mathrm{CaH}_{2}$ and stored over molecular sieves ( $3 \AA$ ) under a $\mathrm{N}_{2}$ atmosphere. Other solvents were dried by passage through a column of activated alumina under $\mathrm{N}_{2}$ using an LC Technology solvent purification system. Yields refer to chromatographically and spectroscopically homogeneous materials, unless otherwise stated. Reactions were monitored by TLC carried out on silica gel plates using UV light as visualising agent and an ethanolic solution of vanillin and ammonium molybdate and heat as developing agents. Silica gel $(60,230-400$ mesh) was used for flash column chromatography. Petroleum ether $=\mathrm{PE}$. NMR spectra were recorded at rt in $\mathrm{CDCl}_{3}$ on a spectrometer operating at $400 \mathrm{MHz}\left({ }^{1} \mathrm{H}\right)$. Epoxide substrates were prepared by literature methods. ${ }^{6}$

\section{Olefination of Epoxides (Tables 1 and 2); General Procedure A (GPA)}

A stirred suspension of epoxide (1 equiv), (S,S)-N, $N^{\prime}$-bis(3,5-di-tertbutylsalicylidene)-1,2-cyclohexanediaminocobalt(II) or test catalyst ( 0.05 equiv), trimethylsulfoxonium iodide ( 3 equiv), and $t$-BuOK ( 3 equiv) in $t-\mathrm{BuOH}\left(10 \mathrm{~mL} / \mathrm{mmol}\right.$ epoxide) was heated at $60{ }^{\circ} \mathrm{C}$ for $4 \mathrm{~h}$. The mixture was allowed to cool to $\mathrm{rt}$, quenched by the addition of sat. aq $\mathrm{NaHCO}_{3}$ solution and extracted with $\mathrm{Et}_{2} \mathrm{O}$. The combined organic extracts were dried (anhyd $\mathrm{MgSO}_{4}$ ) and concentrated in vacuo.

Tandem Corey-Chaykovsky/Epoxide Olefination (Table 3); General Procedure B (GPB)

A stirred suspension of aldehyde (1 equiv), (S,S)-N,N'-bis(3,5-di-tertbutylsalicylidene)-1,2-cyclohexanediaminocobalt(II) (0.10 equiv), trimethylsulfoxonium iodide (10 equiv), and $t$-BuOK (10 equiv) in $t$ $\mathrm{BuOH}\left(10 \mathrm{~mL} / \mathrm{mmol}\right.$ epoxide) was heated at $60{ }^{\circ} \mathrm{C}$ for the time indicated. Products were isolated using the workup as described for olefination of epoxides above and purified by chromatography (silica gel, $\mathrm{EtOAc} / \mathrm{PE}$ ) or identified from crude NMR spectra by reference to literature data.

\section{1-Phenylbut-3-en-2-ol (Table 3, Entry 1)}

Obtained from benzaldehyde ( $30 \mathrm{mg}, 0.28 \mathrm{mmol}$ ) using GPB and purified by chromatography (PE/EtOAc, 1:2) to give an orange oil; yield: $37 \mathrm{mg}$ (89\%).

${ }^{1} \mathrm{H}$ NMR $\left(400 \mathrm{MHz}, \mathrm{CDCl}_{3}\right): \delta=7.38-7.26(\mathrm{~m}, 5 \mathrm{H}), 5.85-5.77(\mathrm{~m}, 1 \mathrm{H})$, 5.20-5.14 (m, 2 H), 4.77-4.73 (m, 1 H), 2.55-2.50 (m, 2 H), 2.02 (d, J = $3.2 \mathrm{~Hz}, 1 \mathrm{H}$ ). Spectroscopic data were in agreement with those previously reported. ${ }^{21}$

\section{Non-1-en-4-ol (Table 3, Entry 2)}

Obtained from hexanal (30 mg, $0.30 \mathrm{mmol}$ ) using GPB and purified by chromatography (PE/EtOAc, 12:1) to give a yellow oil; yield: $36 \mathrm{mg}$ (83\%).

${ }^{1} \mathrm{H}$ NMR $\left(400 \mathrm{MHz}, \mathrm{CDCl}_{3}\right): \delta=5.86-5.78(\mathrm{~m}, 1 \mathrm{H}), 5.15-5.11(\mathrm{~m}, 2 \mathrm{H})$, 3.66-3.63 (m, $1 \mathrm{H}), 2.34-2.27$ (m, $1 \mathrm{H}), 2.17-2.10$ (m, $1 \mathrm{H}), 1.47-1.22$ $(\mathrm{m}, 8 \mathrm{H}), 0.89(\mathrm{t}, J=6.9 \mathrm{~Hz}, 3 \mathrm{H})$. Spectroscopic data were in agreement with those previously reported. ${ }^{22}$

\section{1-(3,5-Dimethoxyphenyl)but-3-en-1-ol (Table 3, Entry 3)}

Obtained using GPB from 3,5-dimethoxybenzaldehyde (30 mg, 0.18 $\mathrm{mmol}$ ) and purified by chromatography (PE/EtOAc, 5:1) to give a yellow oil; yield: $23 \mathrm{mg}(61 \%)$.

${ }^{1} \mathrm{H} \mathrm{NMR}\left(400 \mathrm{MHz}, \mathrm{CDCl}_{3}\right): \delta=6.52(\mathrm{~d}, J=2.0 \mathrm{~Hz}, 2 \mathrm{H}), 6.38(\mathrm{t}, J=2.2$ $\mathrm{Hz}, 1 \mathrm{H}), 5.89-5.76$ ( $\mathrm{m}, 1 \mathrm{H}), 5.20-5.13(\mathrm{~m}, 2 \mathrm{H}), 4.68$ (dd, J = 7.6, 5.1 $\mathrm{Hz}, 1 \mathrm{H}), 3.80$ (s, $6 \mathrm{H}), 2.56-2.43(\mathrm{~m}, 2 \mathrm{H})$. Spectroscopic data were in agreement with those previously reported. ${ }^{23}$

\section{1-(4-Bromophenyl)but-3-en-1-ol (Table 3, Entry 4)}

Obtained using GPB from 4-bromobenzaldehyde ( $30 \mathrm{mg}, 0.16 \mathrm{mmol}$ ) and purified by chromatography (PE/EtOAc) to give a colourless oil; yield: $25 \mathrm{mg}$ (68\%). 
${ }^{1} \mathrm{H}$ NMR $\left(400 \mathrm{MHz}, \mathrm{CDCl}_{3}\right): \delta=7.53-7.46(\mathrm{~m}, 2 \mathrm{H}), 7.26-7.23(\mathrm{~m}, 2 \mathrm{H})$, 5.83-5.73 (m, $1 \mathrm{H}), 5.19-5.15(\mathrm{~m}, 2 \mathrm{H}), 4.72(\mathrm{dd}, J=7.7,5.0 \mathrm{~Hz}, 1 \mathrm{H})$, $4.66(\mathrm{~s}, 1 \mathrm{H}), 2.52-2.41(\mathrm{~m}, 2 \mathrm{H})$. Spectroscopic data were in agreement with those previously reported. ${ }^{24}$

\section{3-(4-Chlorophenyl)hex-5-en-3-ol (Table 3, Entry 5)}

Obtained using GPB from 4'-chloropropiophenone $(50 \mathrm{mg}, 0.30$ $\mathrm{mmol}$ ) and purified by chromatography (PE/EtOAc) to give a yellow oil; yield: $43 \mathrm{mg}(69 \%)$.

${ }^{1} \mathrm{H}$ NMR (400 MHz, CDCl $)$ : $\delta=7.34-7.28(\mathrm{~m}, 4 \mathrm{H}), 5.60-5.49(\mathrm{~m}, 1 \mathrm{H})$, $5.16-5.13(\mathrm{~m}, 2 \mathrm{H}), 2.68-2.65(\mathrm{~m}, 1 \mathrm{H}), 2.47(\mathrm{dd}, J=13.7,8.6 \mathrm{~Hz}, 1 \mathrm{H})$, $1.83-1.80(\mathrm{~m}, 2 \mathrm{H}), 0.75(\mathrm{t}, J=7.4 \mathrm{~Hz}, 3 \mathrm{H})$. Spectroscopic data were in agreement with those previously reported. ${ }^{25}$

\section{1-Allylcyclohexan-1-ol (Table 3, Entry 6)}

Obtained using GPB from cyclohexanone ( $50 \mathrm{mg}, 0.51 \mathrm{mmol}$ ) and purified by chromatography (PE/ EtOAc) to give a yellow oil; yield: 55 $\mathrm{mg}$ (85\%).

${ }^{1} \mathrm{H}$ NMR $\left(400 \mathrm{MHz}, \mathrm{CDCl}_{3}\right): \delta=5.94-5.83(\mathrm{~m}, 1 \mathrm{H}), 5.16-5.08(\mathrm{~m}, 2 \mathrm{H})$, 2.23-2.20 (m, $2 \mathrm{H}), 1.57-1.29(\mathrm{~m}, 10 \mathrm{H})$. Spectroscopic data were in agreement with those previously reported. ${ }^{21}$

\section{Funding Information}

Support from The University of Auckland is gratefully acknowledged through the award of doctoral scholarships to M.L.J. and N.Z.B.

\section{Acknowledgment}

The authors thank Dr Paul A. Hume (SCS, UoA) for helpful discussions.

\section{References}

(1) Reviews: (a) Hess, W.; Treutwein, J.; Hilt, G. Synthesis 2008, 3537. (b) Röse, P.; Hilt, G. Synthesis 2016, 48, 463.

(2) (a) Usman, M.; Ren, Z.-H.; Wang, Y.-Y.; Guan, Z.-H. Synthesis 2017, 49, 463. (b) Wu, X.; Yang, K.; Zhao, Y.; Sun, H.; Li, G.; Ge, H. Nat. Commun. 2015, 6, 1. (c) Barsu, N.; Bolli, S. K.; Sundararaju, B. Chem. Sci. 2017, 8, 2431.

(3) (a) Schaus, S. E.; Brandes, B. D.; Larrow, J. F.; Tokunaga, M.; Hansen, K. B.; Gould, A. E.; Furrow, M. E.; Jacobsen, E. N. J. Am. Chem. Soc. 2002, 124, 1307. (b) Ford, D. D.; Nielsen, L. P. C.; Zuend, S. J.; Musgrave, C. B.; Jacobsen, E. N. J. Am. Chem. Soc. 2013, 135, 15595; and references therein.

(4) Larrow, J. F.; Quigley, P. F. In Comprehensive Chirality; Carreira, E. M.; Yamamoto, H., Eds.; Elsevier: Amsterdam, 2012, 104.

(5) (a) Okuma, K.; Tanaka, Y.; Kaji, S.; Ohta, H. J. Org. Chem. 1983, 48, 5133. (b) Butova, E. D.; Barabash, A. V.; Petrova, A. A.; Kleiner, C. M.; Schreiner, P. R.; Fokin, A. A. J. Org. Chem. 2010, 75, 6229.
(6) Jamieson, M. L.; Hume, P. A.; Furkert, D. P.; Brimble, M. A. Org. Lett. 2016, 18, 468.

(7) (a) Corey, E. J.; Chaykovsky, M. J. Am. Chem. Soc. 1965, 87, 1353. (b) Aggarwal, V. K.; Winn, C. L. Acc. Chem. Res. 2004, 37, 611. (c) Wang, Z. In Comprehensive Organic Name Reactions and Reagents; Wiley: Chichester, 2010, 156.

(8) For another example of a tandem Corey-Chaykovsky reaction sequence, see: Kumar, B. S.; Venkataramasubramanian, V.; Sudalai, A. Org. Lett. 2012, 14, 2468.

(9) (a) Larrow, J. F.; Schaus, S. E.; Jacobsen, E. N. J. Am. Chem. Soc. 1996, 118, 7420. (b) Hansen, K. B.; Leighton, J. L.; Jacobsen, E. N. J. Am. Chem. Soc. 1996, 118, 10924.

(10) Jacobsen, E. N.; Kakiuchi, F.; Konsler, R. G.; Larrow, J. F.; Tokunaga, M. Tetrahedron Lett. 1997, 38, 773.

(11) (a) Schaus, S. E.; Jacobsen, E. N. Tetrahedron Lett. 1996, 37, 7937. (b) Bai, S.; Li, B.; Zhang, X.; Yang, Q.; Li, C. Chem. Sci. 2012, 3, 2864. (c) White, D. E.; Tadross, P. M.; Lu, Z.; Jacobsen, E. N. Tetrahedron 2014, 70, 4165.

(12) (a) Hinterding, K.; Jacobsen, E. N. J. Org. Chem. 1999, 64, 2164. (b) Denmark, S. E.; Ahmad, M. J. Org. Chem. 2007, 72, 9630. (c) North, M.; Quek, S. C. Z.; Pridmore, N. E.; Whitwood, A. C.; Wu, X. ACS Catal. 2015, 5, 3398.

(13) (a) Mahadevan, V.; Getzler, Y. D. Y. L.; Coates, G. W. Angew. Chem. Int. Ed. 2002, 41, 2781. (b) Getzler, Y. D. Y. L.; Mahadevan, V.; Lobkovsky, E. B.; Coates, G. W. J. Am. Chem. Soc. 2002, 124, 1174. (c) Schmidt, J. A. R.; Mahadevan, V.; Getzler, Y. D. Y. L.; Coates, G. W. Org. Lett. 2004, 6, 373. (d) Getzler, Y. D. Y. L.; Mahadevan, V.; Lobkovsky, E. B.; Coates, G. W. Pure Appl. Chem. 2004, 76, 557. (e) Schmidt, J. A. R.; Lobkovsky, E. B.; Coates, G. W. J. Am. Chem. Soc. 2005, 127, 11426.

(14) (a) Nielsen, L. P. C.; Stevenson, C. P.; Blackmond, D. G.; Jacobsen, E. N. J. Am. Chem. Soc. 2004, 126, 1360. (b) Nielsen, L. P. C.; Zuend, S. J.; Ford, D. D.; Jacobsen, E. N. J. Org. Chem. 2012, 77, 2486.

(15) Note that all reactions were conducted under anhydrous conditions, which was determined to be important to obtain high conversion in all ylide reactions, see the experimental section for details.

(16) Sipos, G.; Drinkel, E. E.; Dorta, R. Chem. Soc. Rev. 2015, 44, 3834.

(17) Weber, L. Angew. Chem. Int. Ed. 1983, 22, 516.

(18) Burtoloso, A. C. B.; Dias, R. M. P.; Leonarczyk, I. A. Eur. J. Org. Chem. 2013, 5005.

(19) Mangion, I. K.; Weisel, M. Tetrahedron Lett. 2010, 51, 5490.

(20) Bellow, J. A.; Stoian, S. A.; van Tol, J.; Ozarowski, A.; Lord, R. L.; Groysman, S. J. Am. Chem. Soc. 2016, 138, 5531.

(21) Guijarro, D.; Mancheño, B.; Yus, M. Tetrahedron 1992, 48, 4593.

(22) Schmidt, B. J. Org. Chem. 2004, 69, 7672.

(23) Chen, J.; Liu, D.; Fan, D.; Liu, Y.; Zhang, W. Tetrahedron 2013, 69, 8161.

(24) Li, S.; Wang, J.-X.; Wen, X.; Ma, X. Tetrahedron 2011, 67, 849.

(25) Schneider, U.; Kobayashi, S. Angew. Chem. Int. Ed. 2007, 46, 5909. 